\title{
Economic Justification of Enterprise Development based on Company Value Analysis
}

\author{
Natalia A. Shcherbakova*, and Alexander Shcherbakov \\ Novosibirsk State Technical University, Novosibirsk, Russia
}

\begin{abstract}
The article considers the use of company value analysis for economic justification of the choice of directions for business development. The company value analysis is based on income forecasting. The authors outline the features of income modelling for these purposes. They consider various ways of forecasting the income of an enterprise for the purpose of economic justification of development options based on annual and quarterly values. The article suggests that the current pandemic situation in the world has significantly affected the performance and development prospects of almost every company making it harder to forecast the performance based on retrospective data due to dramatic changes in income caused by the socio-economic environment in the world. The authors arrived at the conclusion that each specific scenario requires the use of a number of forecast options and selection of the most appropriate forecasting model with regard to every particular situation. In conclusion, it was pointed out that the value analysis of the company gives evident results and can be considered as an effective tool for economic justification of the choice of directions for business development.
\end{abstract}

Keywords: company value analysis, value-based management, enterprise value, enterprise development, economic justification.

\section{Introduction}

The relevance of the study is determined by the fact that in modern conditions the approaches to assessing the effectiveness of company performance are being transformed. More and more researchers are turning from the classical indices of financial and economic analysis to the issues of business value chain, that is, so-called value analysis. An attempt has been made within the present study of company's value analysis to clarify the tools of economic justification of development options, which seems to be quite relevant.

The growth of business value is considered as the main characteristic of business management effectiveness and the main indicator of company's success. The dynamics of changes in value is an effective tool for making management decisions. The direction called

\footnotetext{
*Corresponding author: serbakova.n@gmail.com
} 
value-based management is being actively developed. The article discusses the technology of applying this methodology for economic justification of a business development options.

\section{Progress level in the subject research}

Recently, the views about evaluation of a business's efficiency and its development options are changing. Many researchers conclude that classically calculated economic indicators, indicators of financial and economic analysis in particular, do not allow to adequately assessing the performance of a company. The real effectiveness of activities and the choice of development directions should lead to the increase in company value. This thesis has been well documented by scholars from around the world [1-3]. Among the economists who have contributed to the study of various aspects of value-based management are T. Copeland, A. Damodaran, T. Koller, N. Antilla and K. Lee [6], V.G. Kogdenko, I.V. Ivashkovskaya, V.A. Shcherbakov.

The advantages of using the value indicator to assess a company's performance are the following: firstly, the company value is measurable; secondly, it reflects the increase in the well-being of shareholders [4-6]. The last and most important aspect is that it takes into account not only the current, but also the long-term results of the enterprise, which is crucial in determining areas of a company's development. Existing studies are primarily aimed at assessing the company value and its change as a whole [7-9]. In this article, the authors examine the applicability of company's value analysis to a particular aspect - the economic justification of the choice of directions for company development.

The novelty of the research is the development of economic and mathematical models for the justification of areas of a company's development based on the methodology of company value analysis.

The article presents the results of a study conducted by the authors in the field of clarifying the concept of value-based management and developing tools for value analysis. The main objectives of the article can be interpreted as follows:

- present the value analysis as a relevant effective method for assessing the company's efficiency and an effective tool for economic justification of areas of a company's development;

- clarify the tools for economic justification of directions for business development based first of all on a precise identification of a comparison base that requires statistical modeling of a business income.

The theoretical relevance of the work concerns systematization and clarification of theoretical assumptions in terms of methodological approaches to making calculations for economic justification of areas of a company's development. The key hypothesis of the study is the statement that in the modern economy the company value analysis can provide a correct and objective way to choose the areas for a company's development.

The practical relevance is to test the developed economic and mathematical models using the data from actual Russian companies. In particular, the paper discusses the possibility of obtaining reasonable sales forecasts and other key indicators of companies' economic activities. The requirements of accuracy and validity to applying the corresponding analytical models should, however, be given a priority in these model calculations. The economic and mathematical models proposed in the article as well as the criteria for management decisions make it possible to more objectively evaluate selection of the areas for enterprise development.

Research methodology. The framework of the study included three main stages. The first stage was made up of selection of the revenue parameter for forecasting. The second stage consisted of formation of an economic-mathematical model of calculation and its testing on the data of a real company. The third stage was the adjustment of the trend values if necessary. 
The research involved general research methods such as the method of ascending from the abstract to the concrete, the methods of comparison, observation, and scientific generalization. The method of ascending from the abstract to the concrete was chosen since there was needed a transition from theoretical principles to practical aspects, to the study of specific companies. The comparison method was used as the most important analysis method, allowing evaluating, in particular, individual aspects of the company's activities and the effectiveness of its functioning as a whole based on comparison of absolute and relative values. The observation method was used because the research provided monitoring real objects, namely, data from real companies. The method of scientific generalization was employed, since there is logic in transition from the singular to the general; in this case, to the specifics of the functioning of individual companies as a whole.

In addition, when carrying out model calculations, special econometric methods were also used: approximations and extrapolations based on the construction of linear trends, statistical estimation of reliability of forecast results.

\section{Features of income forecasting for the economic justification of the company's development options}

For economic justification of decisions about a company's development options on the basis of the company value analysis methodology, it is proposed to compare the company value in the situation 'as it is' and in the situation when a company's development direction changes. The situation is called 'as it is' when a company is functioning without significant changes, i.e. without shifting to new development options. The calculation of the sought value for choosing a development option is based on forecasts of its income.

The purposes of the study required the annual and quarterly revenue figures for the years of 2015-2018, which were taken from the annual company reports. (Table 1).

Table 1. Retrospective revenue of OJSC Slavneft Oil and Gas Company, million roubles.

\begin{tabular}{|c|c|c|c|c|}
\hline Indicators & $\mathbf{2 0 1 5}$ & $\mathbf{2 0 1 6}$ & $\mathbf{2 0 1 7}$ & $\mathbf{2 0 1 8}$ \\
\hline Annual Sales & $11,211.89$ & $13,301.38$ & $17,532.80$ & $19,432.09$ \\
\hline Sales for Quarter 1 & 2777.02 & 2915.86 & 3837.48 & 4162.05 \\
\hline Sales for Quarter 2 & 2706.47 & 3297.36 & 4125.42 & 5091.01 \\
\hline Sales for Quarter 3 & 2903.26 & 3427.93 & 4703.10 & 5675.66 \\
\hline Sales for Quarter 4 & 2825.15 & 3660.22 & 4866.80 & 4503.37 \\
\hline
\end{tabular}

Source: compiled by the authors from the company's data

For the purposes of the study, we forecast the sales of the enterprise for 2019-2021 in the 'as it is' situation based on annual and quarterly revenue data. It should be taken into account that the above given data are time series, since each quarter (year) has its own value for the income indicator which repeats at regular intervals [10].

Provided that the company under consideration is not a subject to seasonal changes in revenue, we can use the simplest pairwise linear regression model to determine the trend in 
revenue changes. As $y$ in the case of economic justification of the development options for the company, we can use any indicators that vary depending on the analyzed development option (sales, profit, others), as $x$ - the numbers of historical periods for the time series.

The pairwise linear regression model is as follows (1):

$$
y=\beta_{0}+\beta_{1} x+\epsilon,
$$

where $\beta_{0}, \beta_{1}$ - model parameters, $\epsilon$ - random variable indicating error, $x$-time periods, $y-$ revenue for the past period of time. An equation that describes how the expected value of $y$ depends on $x$ is called a regression equation (in this case, the graph of the equation will be a straight line) and is written as (2):

$$
\hat{\mathrm{y}}=\beta_{0}+\beta_{1} x
$$

where $\beta_{0}$-regression line bias, $\beta_{0}$ - slope, $\hat{y}$ - expected (average) value for a given $x$ value.

To determine the coefficients $\beta_{0}, \beta_{1}$ of the regression equation, we will use the least squares method, which consists in minimizing the squared deviations of the observed values from the expected ones (3):

$$
\sum\left(y_{i}-\hat{y}_{i}\right)^{2} \text {. }
$$

The minimization of this function is carried out by the methods of differential calculus using partial derivatives for each of the variables entering the function. Thus, we obtain the following formulae for determining the parameters that minimize this function (4) [10]:

$$
\beta_{1}=\frac{\sum\left(x_{i}-\bar{x}\right)\left(y_{i}-\bar{y}\right)}{\sum\left(x_{i}-\bar{x}\right)^{2}}, \beta_{0}=\bar{y}-\beta_{1} x,
$$

where $x_{i}$ - independent variable value, $y_{i}$ - observed value of the dependent variable, $\bar{x}-$ mean value of the independent variable, $\bar{y}$ - average value of the dependent variable.

Now, it is necessary to determine the method to evaluate the quality of the constructed model. The conventional method in economics for determining the quality measure of a model is the coefficient of determination, $R^{2}$.

$S S E=\sum\left(y_{i}-\hat{y}_{i}\right)^{2}-$ measure of error in predicting the values of a dependent variable.

$S S T=\sum\left(y_{i}-\bar{y}\right)^{2}-$ measure of error when using the average $\bar{y}$ to predict the values of the dependent variable.

$S S R=\sum\left(\hat{\mathrm{y}}_{i}-\bar{y}\right)^{2}-$ a measure of the deviation of the expected value $\hat{\mathrm{y}}_{i}$ from the average $\bar{y}$. SSE, SST and SSR related as follows: SST $=\mathrm{SSR}+\mathrm{SSE}$. Thus, the determination coefficient $R^{2}$ is defined as follows: $R^{2}=\frac{S S R}{S S T}, R^{2} \epsilon(0,1)$.

To identify the trend in revenue changes in the 'as it is' situation, we use the described pairwise linear regression model and the data of Table 1. As y in this case of the economic justification of a company's development options, we take the revenue by years for model 1 and the quarterly revenue for model 2, respectively, as $\mathrm{x}$ are the numbers of years or quarters of the history. The results are shown in Fig.1-3. 


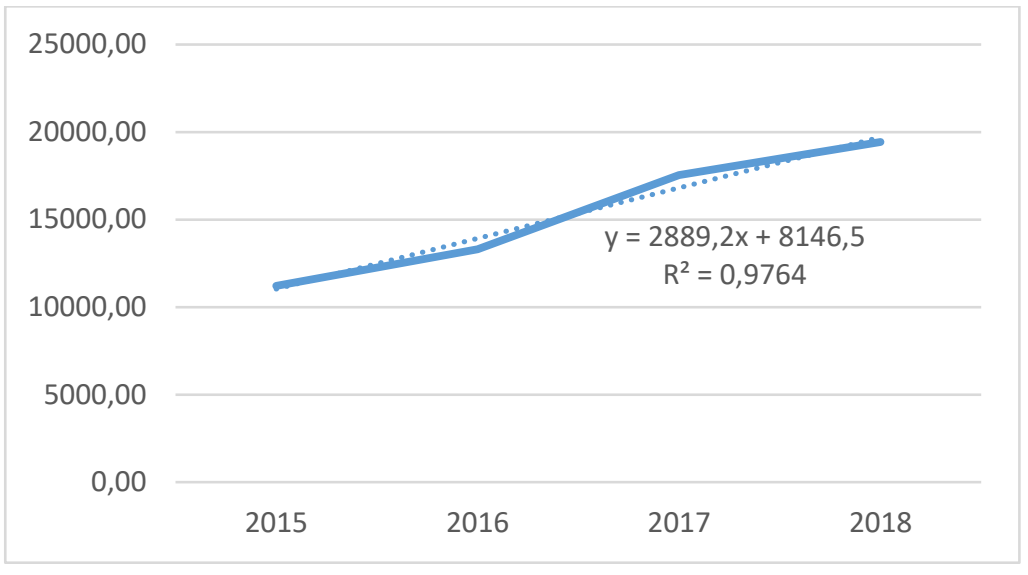

Fig. 1. Construction of a linear regression model of revenue based on annual values (Model 1), million roubles.

The graph shows the regression equation and the determination coefficient value R2. Since the value of the determination coefficient is quite close to 1 , the resulting model can be used to predict future values.

Similarly, we construct and evaluate the model for quarterly revenue.

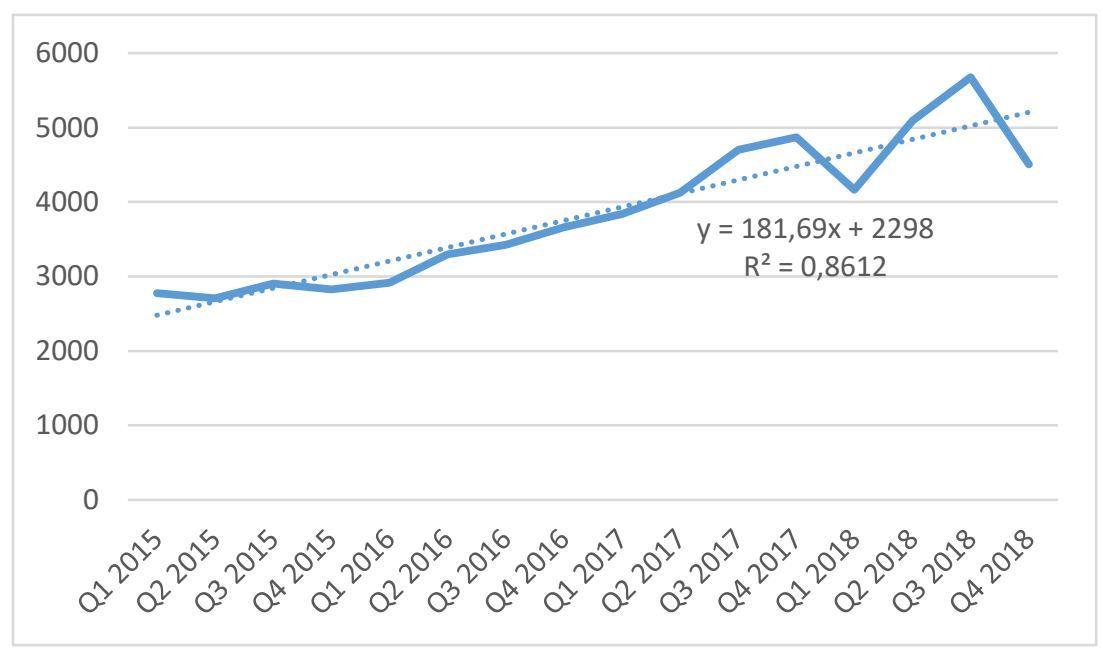

Fig. 2. Construction of a linear regression model of revenue based on quarterly values (model 2), thousand roubles.

The value of the determination coefficient, as in the previous model, is quite close to 1 which means that this model can also be used to predict future values. 


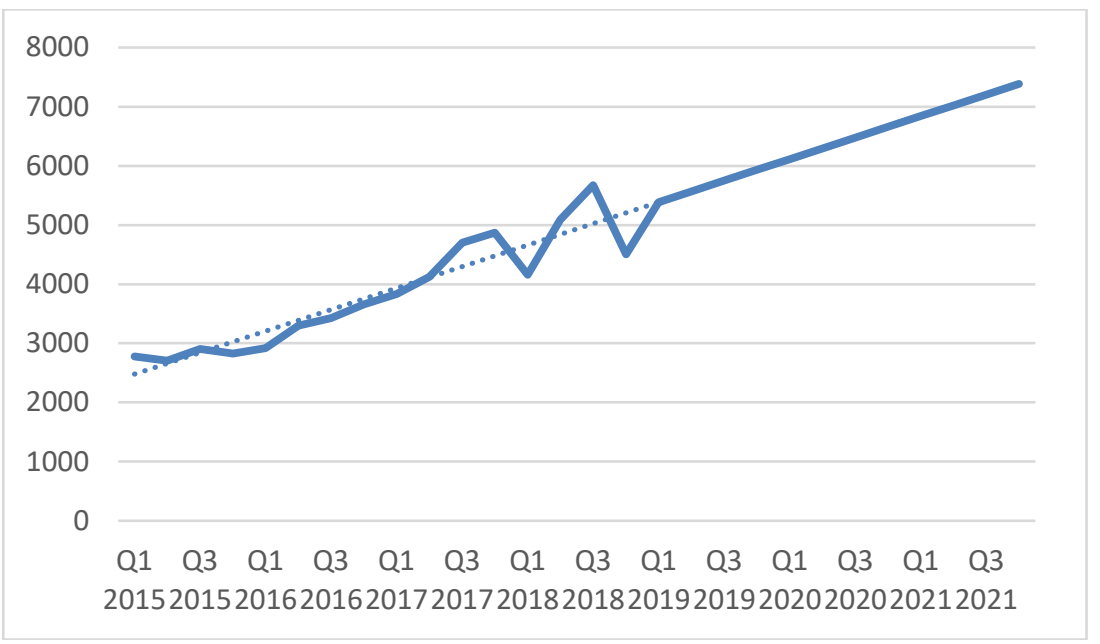

Fig. 3. Revenue forecasting based on quarterly values (Model 2), thousand roubles.

Trends in quarterly and annual revenue are slightly different (Figures 1-3).

The results of revenue forecasting using the constructed models are presented in Table 2.

Table 2. Forecasted revenue of OJSC Slavneft Oil and Gas Company (Model 2, forecast based on quarterly revenue data), million roubles.

Source: compiled by the authors based on research materials

\begin{tabular}{|c|c|c|c|}
\hline Indicators & $\mathbf{2 0 1 9}$ & $\mathbf{2 0 2 0}$ & $\mathbf{2 0 2 1}$ \\
\hline Annual Sales & $22,637.06$ & $25,544.72$ & $28,451.14$ \\
\hline Sales for Quarter 1 & 5386.73 & 6113.49 & 6840.25 \\
\hline Sales for Quarter 2 & 5568.42 & 6295.8 & 7021.94 \\
\hline Sales for Quarter 3 & 5750.11 & 6476.87 & 7203.63 \\
\hline Sales for Quarter 4 & 5931.80 & 6658.56 & 7385.32 \\
\hline
\end{tabular}

Let us compare the obtained data on the revenue forecast for the enterprise based on annual and quarterly data (Table 3 ).

Table 3. Analysis of forecast revenue), million roubles.

\begin{tabular}{|c|c|c|c|}
\hline Indicators & $\mathbf{2 0 1 9}$ & $\mathbf{2 0 2 0}$ & $\mathbf{2 0 2 1}$ \\
\hline $\begin{array}{c}\text { Forecasted Sales for } \\
\text { model 1 (annual forecast), } \\
\text { million roubles }\end{array}$ & $22,592.50$ & $25,481.70$ & $28,370.90$ \\
\hline $\begin{array}{c}\text { Forecasted Sales for } \\
\text { model 2 (based on } \\
\text { quarterly data), million } \\
\text { roubles }\end{array}$ & $22,637.06$ & $25,544.72$ & $28,451.14$ \\
\hline
\end{tabular}




\begin{tabular}{|c|c|c|c|}
\hline $\begin{array}{c}\text { Differences in forecasts, } \\
\text { million roubles }\end{array}$ & 44.56 & 63.02 & 80.24 \\
\hline $\begin{array}{c}\text { Differences in forecasts, } \\
\%\end{array}$ & 0.20 & 0.25 & 0.28 \\
\hline
\end{tabular}

Source: compiled by the authors based on research materials

Thus, the differences in the forecast values for this company are insignificant, within the range of $0.2-0.28 \%$. The value of the determination coefficient is greater for a linear regression model built based on annual revenue values $(\mathrm{R} 2=0.9764$ relative to $\mathrm{R} 2=0.8612$ when forecasting based on quarterly values of the indicator under study). The decrease in accuracy of the second model is due to some variation in values by quarters.

According to the results of the study, it can be concluded that both forecast variants give acceptable accuracy, while in the case of forecasting based on annual indicators, quarterly fluctuations are smoothed. Thus, for each specific situation, it is necessary to select the most appropriate model that takes into account or disregards seasonal fluctuations and other factors.

Thus, the value of R2 in both cases is close enough to 1 . Therefore, both models can be used to predict values. However, in Model 2 the forecast accuracy is lower. This can be explained by some variation in revenue by quarters due to seasonal fluctuations, although insignificant. Hence, with strong seasonal fluctuations the forecasts in the 'as it is' situation require other models to be selected. For income forecasts of company development options that involve a significant change in activity, revenues are forecast primarily by direct translation using the discounted flow methodology to estimate the value of the company considered.

The calculations are based on the classical discounted cash flow method and the terminal value accounting method using the Gordon model (formula 5) [11]:

where

$$
V=\sum_{i=1}^{n} \frac{F C F F_{i}}{(1+D R)^{i}}+\frac{F C F F_{n} \cdot(1+g)}{(1+D R)^{n} \cdot(D R-g)}-D_{0},
$$

$i$ - year number after the valuation date;

$n$ - number of years within the forecast period;

$F C F F_{i}$ - free cash flow to firm of the $i$-th forecast year;

$D R$ - discount rate;

$g$ - long-term capital gain rate in the post-forecast period;

$D_{0}-$ debt (borrowed capital value) as of the valuation date.

In some cases, it is possible to adjust trends taking into account industry development forecasts or the assumption of the company's top managers of the income parameters changing.

The development option for the company in which the difference in the company value 'as it is' and in the case of adopting a specific development option is maximum, can be considered a priority. The value indicator is clear and takes into account the development prospects of the company.

\section{Conclusion}

The results obtained prove that the goals of the research have been achieved.

Based on the study, it was concluded that higher accuracy of the forecasting model based on annual values of indicators is because quarterly fluctuations are smoothed in this case, and that in some cases it is necessary to abandon forecasting models and use the direct conversion method. The current pandemic situation in the world has a significant impact on the results 
of operations and development prospects of almost every company. It also complicated the forecasting process based on retrospective data due to sharp changes in income caused by the socio-economic situation in the world. The authors of the article have arrived at the conclusion that for each specific situation it is necessary to use several forecast options and select the most appropriate forecasting model that is able to take into account the factors necessary in a particular situation. According to the authors of this article, for economic justification of such changes, it is advisable to use company value analysis. The increase in value concerning the situation 'as it is' indicates the effectiveness of the chosen option for a company development. Moreover, the forecast of income in the situation 'as it is', which can serve a benchmark, can be carried out on the basis of a linear regression model, provided that the parameters for assessing its quality have acceptable values. It should be noted that in the case of seasonality as well as other reasons for fluctuations in the company's revenues over time periods, in each specific situation it is necessary to select the most appropriate model for forecasting, taking into account or not taking into account seasonal fluctuations and other factors affecting the amount of income.

In general, company value analysis is complicated by the need to predict a long-term income flow, but it gives clear results and is an effective tool for economic justification of the choice of directions for business development.

\section{References}

1. S.A. Ross, R.W. Westerfield, J.F. Jaffe, Corporate Finance (10th ed. McGrawHill/Irwin, 2013)

2. R. Brealey, S. Myers, F. Allen, Principles of Corporate Finance (11th ed., McGrawHill/Irwin, 2014)

3. D.L. Volkov Value-based management theory: financial and accounting aspects (2nd ed., SPb., 2008) [in Russian]

4. A. Damodaran, Investment Philosophies: Successful Strategies and the Investors. Who Made Them WorkInvestment Philosophies (2nd ed., Wiley, 2012)

5. A. Damodaran. Investment Valuation: Tools and Techniques for Determining the Value of Any Asset. (Mc-Graw-Hill, 2002)

6. T. Koller, M., Goedhart, D. Wessels, McKinsey \& Company Inc., Valuation Measuring and Managing the Value, (6th ed., JohnWiley \& Sons, Inc., Hoboken, New Jersey, 2015)

7. J.B. Abrams, Quantitative Business Valuation: A Mathematical Approach for Today's Professionals (Moscow, Laboratoriya Knigi, 2014)

8. Nick Antill, Kenneth Lee. Company Valuation Under IFRS: Interpreting and Forecasting Accounts Using International Financial Reporting Standards. (2nd ed. Hampshire, Harriman House, 2013)

9. K. Dodel, Private Firm Valuation and M\&A: Calculating Value and Estimating Discounts in the New Market Environment. (Wiley, 2014)

10. D.R. Anderson, D.J. Sweeney, T.A. Williams, Statistics for Business and Economics. (Mason, South-Western Cengage Learning, 2012)

11. N.A. Shcherbakova, V.A. Shcherbakov, Formation of Cash Flow-Based Factor Models in the System of Value-Based Management, in Proceedings of the International Scientific Conference "Far East Con" (ISCFEC 2020), Series: Advances in Economics, Business and Management Research, 128, 743-751 (2020) 